\title{
Low Temperature Microplasma Jet at Atmospheric Pressure for Inducing Surface Modification on Polyethylene Substrates
}

\author{
E. C. B. B. $\operatorname{Aragão}^{1}$, J. C. Nascimento ${ }^{1}$, A. D. Fernandes ${ }^{1}$, F. T. F. Barbosa ${ }^{1}$, D. C. Sousa ${ }^{1}$, \\ C. Oliveira ${ }^{1,2}$, G. J. P. Abreu ${ }^{1}$, V. W. Ribas ${ }^{1}$, B. N. Sismanoglu, ${ }^{1, *}$ \\ ${ }^{1}$ Technological Institute of Aeronautics (ITA), Physics Department, São José dos Campos, Brazil \\ ${ }^{2}$ Laboratório Nacional de Ciência e Tecnologia do Bioetanol-CTBE/CNPEM, Campinas, Brazil
}

\begin{abstract}
An atmospheric pressure ac microplasma jet device with $\mathrm{Cu}$ spiral-torsion-spring type electrodes was developed. This electrode geometryenables the generation of low power and stable micro plasma jet operated in $\mathrm{Ar}, \mathrm{He}, \mathrm{O}_{2}, \mathrm{~N}_{2}$ and air at flux rates ranging from 2 to $12 \mathrm{~L} / \mathrm{min}$, applying an ac high voltage at $60 \mathrm{~Hz}$ frequency. Moreover, the device is absent of dielectric parts which prevents contamination of the plasma. To observe the outflow pattern a Schlieren photography system was used, resulting in broaden and continuous laminar gas flow. Optical emission spectroscopy measurements allow us to infer the mean gas temperature of plasma jet from the outer electrode along its axial position. A temperature decrease of $110^{\circ} \mathrm{C}$ to $40^{\circ} \mathrm{C}$ was observed up to $5 \mathrm{~mm}$ and beyond this gas temperature the plasma jet reaches room temperature, so enabling it to use in treatment of heat-sensitive surfaces such as biomaterials and polymers like polyethylene.
\end{abstract}

Keywords Microplasma jet, Schlieren photography, Gas temperature, Optical emission spectroscopy, Polyethylene

\section{Introduction}

Atmospheric Pressure Microplasma Jet (APMJ) can be generated through a number of configurations, generally using noble gases [1-14]. The APMJ are suitable for industrial and research applications, such as surface modification, biological material sterilization, biomedical applications (dermatological, dental, etc.), ozone formation and treatment of heat-sensitive materials [8]. In general, APMJ is produced between planar or tube-type shape electrodes and the gas flow expulses the plasma into the ambient air, strongly reducing the gas temperature (much lower than the electron temperature) allowing several other applications [8]. McKenna et al. [15] used two different atmospheric pressure microplasma systems for surface engineering of a range of nanomaterials. Specifically a gas-phase approach from vaporized tetramethylsilane has been used to synthesize silicon carbide nanoparticles with diameters below $10 \mathrm{~nm}$. Microplasma-liquid system has been used to tailor surface properties of silicon nanoparticles and to reduce graphene oxide into graphene. Gregório et al. [16] presents an imaging analysis of stable microplasmas produced in air, argon, and helium at atmospheric pressure,

* Corresponding author:

bogos@ita.br (B. N. Sismanoglu)

Published online at http://journal.sapub.org/ajcmp

Copyright $(2014$ Scientific \& Academic Publishing. All Rights Reserved using a continuous microwave $(2.45-\mathrm{GHz})$ excitation. The

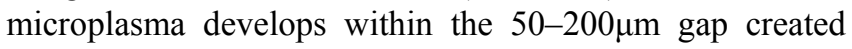
between two metal electrodes ( $6 \mathrm{~mm}$ in length), placed at the open end of the transmission line. Zhu et al. [17] used a direct current, non-thermal atmospheric-pressure microplasma with $\mathrm{He} / \mathrm{O}_{2}$ gas mixture to characterize the electrical properties as a function of the oxygen concentration. They observed a self-pulsed mode (negative resistivity) before the transition of the discharge to normal glow mode. Optical emission spectroscopy (OES) was used from both end-on and side-on along the plasma to analyze the reactive species generated in the plasma, which allows for enhanced applications in health and medical related areas. Hong et al. [18] presents an atmospheric-pressure $\mathrm{N}_{2}$-plasma jet generated from microdischarges in a porous dielectric. A plasma jet with a length of $42 \mathrm{~mm}$ was produced by feeding nitrogen gas through a porous alumina installed between an outer electrode and a hollow inner electrode and by applying $60 \mathrm{~Hz}$ sinusoidal voltage wave to the electrodes. Microdischarges in the porous alumina are ejected as a plasma jet from the outer electrode through a $1 \mathrm{~mm}$ hole by increasing the applied voltage, showing that the temperature of the jet decreases to a value close to room temperature. Benedikt et al. [19] developed an RF microplasma jet working at atmospheric pressure for thin film deposition. One capillary tube was excited by an RF frequency of $13.56 \mathrm{MHz}$ at rms voltages of around $200-250 \mathrm{~V}$. The plasma was generated in a plasma forming gas ( $\mathrm{He}$ or $\mathrm{Ar}$ ) in the 
annular space between the capillary and the ceramic tube. The electron number densities were around $8 \times 10^{20} \mathrm{~m}^{-3}$, measured using optical emission spectroscopy. The gas temperature $T_{g}$ stays below 400K. Deposition of hydrogenated amorphous carbon films and silicon oxide films has been tested using $\mathrm{Ar} / \mathrm{C}_{2} \mathrm{H}_{2}$ and $\mathrm{Ar} /$ hexamethyldisiloxane/ $\mathrm{O}_{2}$ mixtures, respectively. Mohamed et al. [20] performed microplasma where the electrode's opening was about $200 \mu \mathrm{m}$ diameter. They measured $T_{g}$ by evaluating the rotational $(0-0)$ band of the second positive system of $\mathrm{N}_{2}$. Sismanoglu et al. [3, 4] and Gomes et al. [5] studied electrical parameters of relatively high pressure microplasmas, showing the different modes of operation, the pre-breakdown and breakdown behaviors and the main gas parameters. For pressures ranking from 90 to 800 Torr of $\mathrm{Ar}$ flow at $0.031 . \mathrm{min}^{-1}$ and currents from 5 to $20 \mathrm{~mA}$, OES measurements results electron number density $n_{e} \sim 10^{14} \mathrm{~cm}^{-3}$, $T_{g} \sim 650 \mathrm{~K}$ and excitation temperature $T_{\text {exc }} \sim 8000 \mathrm{~K}$. By flowing gas at $0.71 . \mathrm{min}^{-1}$, microhollow cathode-type microplasma yields for $n_{e}\left(2-4 \times 10^{14} \mathrm{~cm}^{-3}\right), T_{g}(460-640 \mathrm{~K})$, $T_{\text {exc }}(\sim 7000 \mathrm{~K})$, when the discharge current $\left(I_{d}\right)$ ranges from 7 to $15 \mathrm{~mA}$ [3].

The alternating current (ac) operating APMJ produced in the past few years presents characteristics of cold plasma and are suitable for various applications [9, 10, 13, 14]. Nevertheless, the nozzle cross-sectional area has diameter less than $1 \mathrm{~mm}$ because generally is used a micro perforated hole in plane electrode foils through which the gas is flowing. In the majority of these devices, the feed gas was nitrogen and the plasma is generated applying an ac high voltage of high frequency. Hong et al. [9] developed ac APMJ operated at $20 \mathrm{kHz}$ in microhollow cathode discharge with hole of $500 \mu \mathrm{m}$ diameter, suitable for $\mathrm{N}_{2}$ gas. Long plasma jets of up to $6.5 \mathrm{~cm}$ operated at $6.3 \mathrm{~L} / \mathrm{min}$ and gas velocity of $535 \mathrm{~m} / \mathrm{s}$ were reported. Giuliani et al. [13] used the same configuration, but with hole diameter of $1 \mathrm{~mm}$, operated at $60 \mathrm{~Hz}$ and with flow rate of about $10 \mathrm{~L} / \mathrm{min}$ (power of $5-$ $13 \mathrm{kV}$ ) of air. Recently, Hong et al. [14] modified this device, incorporating porous alumina at the exit nozzle, but maintaining $1 \mathrm{~mm}$ in hole diameter of the tubular electrode. They used nitrogen as the working gas. Kim et al. [10] produced ac APMJ operated at $20 \mathrm{kHz}$ with $\mathrm{N}_{2}$ as feed gas. The anode was made with eightmicro holes, each with diameter of $200 \mu \mathrm{m}$ and the input voltages was ranging from 5.5 to $9.5 \mathrm{kV}$. Hong et al. [21] fabricated also an ac APMJ device operating at $20 \mathrm{kHz}$ with $\mathrm{N}_{2}$ gas and diameter of the hole in the outer electrode $-700 \mu \mathrm{m}$.

In this work, APMJ device was easily fabricated in a pencil-type device to produce stable cold plasma suitable for applications and research in a low manufacturing cost. The main difference of this device in comparison with the previously cited is the ability to operate with molecular and atomic (noble) gases, including compressed air, at lower power consumption, lower gas flow, low frequency and good stability. This is possible due the electrode geometry that has a spiral-torsion-spring shape with diameter of $2.5 \mathrm{~mm}$ that allows broadening of the microplasma jet at the exit hole. Polyethylene organic substrates have been used to investigate the surface modification applying APMJ. The surface modification was observed through Water Contact Angle (WCA) measurements.
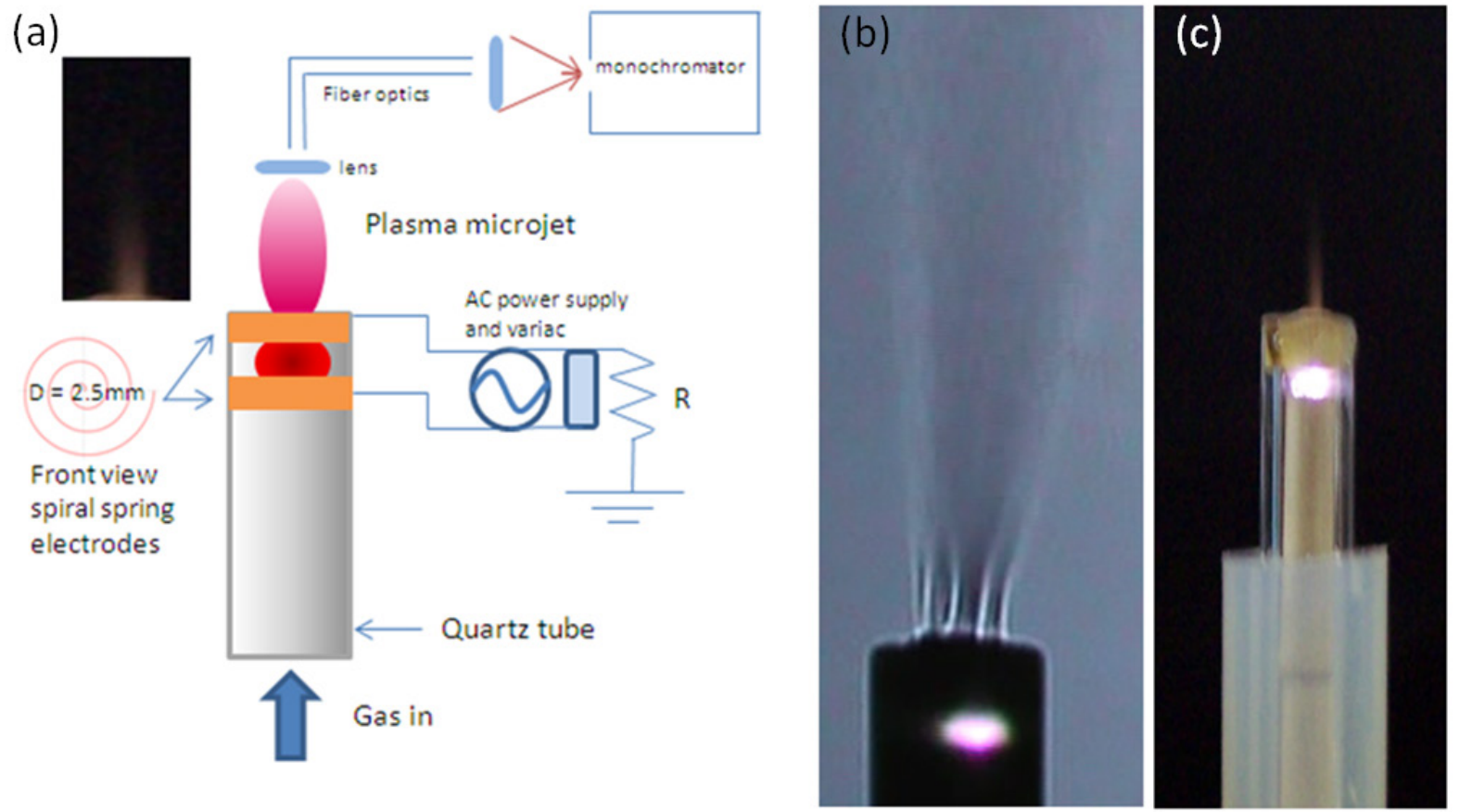

Figure 1. (a) Schematic representation of the microplasma jet generated by spiral-torsion-spring electrodes and the schematic representation of the electrical circuit (the inset represents the photograph of air plasma jet). (b) Schlieren image of the plasma laminar outflow and (c) Picture showing the $\mathrm{N}_{2}$ microplasma jet and the bright glow discharge between electrodes 


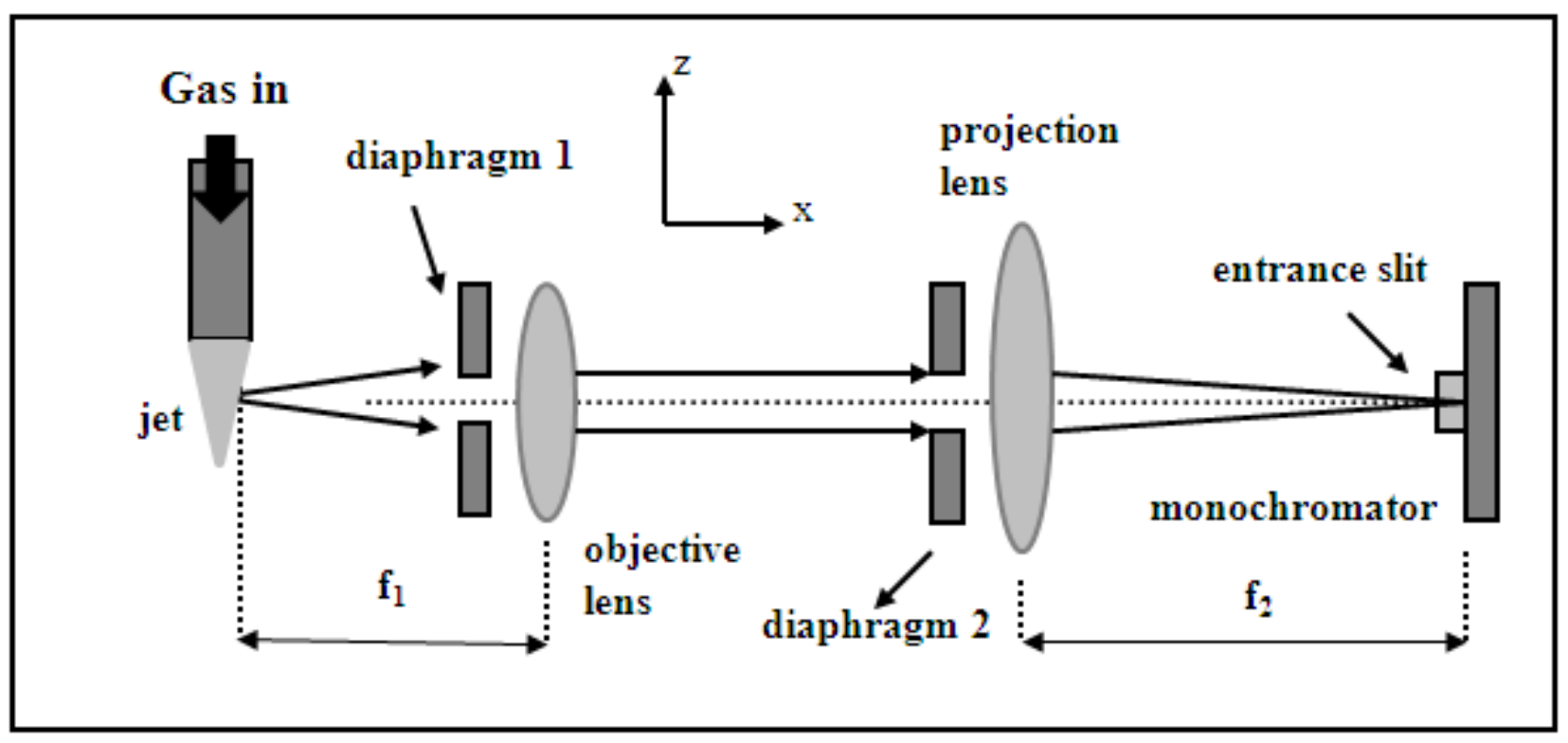

Figure 2. Experimental set-up of spatially resolved optical emission spectroscopy

\section{Experimental}

One can see in Fig. 1 the schematic of the experimental set-up where the two spring spiral torsion-type $\mathrm{Cu}$ electrodes are separated each other by $1 \mathrm{~mm}$. The spiral electrode is wound flat, with rectangular section material (width $b=$ $1.5 \mathrm{~mm}$, and thickness $t=30 \mu \mathrm{m}$ ) with constant space between the coils, through which the gas is flowing. The electrodes are arranged parallel and are inserted in a quartz tube (the tube can be substituted by glass) with $2.6 \mathrm{~mm}$ inner diameter (the nozzle cross-sectional area) and the inter electrode distance is about $1.2 \mathrm{~mm}$. Generally, dielectric is used to fill this gap in dc or ac micro plasmas, but our micro jet is free from dielectric taking advantage on its fabrication and, in addition, preventing from contamination of the plasma with sputtered materials. The ac power supply used in this work is transformer for neon light operated at $60 \mathrm{~Hz}$ $(20 \mathrm{kV}, 40 \mathrm{~mA})$, coupled with a variable autotransformer in order to avoid excessive current and to allow voltage control.

To observe the outflow patterna Schlieren photography system was mounted [22]. The latter allows to identify and characterize the free-gas-stream or the plasma plume and it consequent transition from laminar to turbulent flow. The outflow plasma behavior is monitored trough the refraction index of the emitted radiation. In the discussed configuration, the light emitted by the neon lamp is collimated and focused onto spherical mirror, traversing the plasma region. Thus, the light beam is distorted, creating a spatial variation in the intensity of the light, which can be visualized by a digital camera.

Fig. 2 presents schematically the experimental setup used to perform OES measurements of APMJ. The plasma was confined between the electrodes, burning freely in air at atmospheric pressure (709 Torr in the laboratory) and was composed by the main gas and high-purity $1 \% \mathrm{H}_{2}$. The addition of $\mathrm{H}_{2}$ makes it possible to estimate the electron number density of the plasma from the broadening of the hydrogen atom $\mathrm{H}_{\beta}$ line. The gas connections were controlled by means of mass flow controllers and a series ballast resistor of $47 \mathrm{k} \Omega$ was connected to the cathode to obtain electrical characteristics. A Keithleypicoammeter model 414S, a Minipa digital voltmeter and a HP 6920B DC power supply were used to develop the experimental part.

For obtaining the optical spectruma Jobin-Yvon monochromator was used (numerical aperture of $0.13-\mathrm{f} / 7.5$ ) with entrance slit fixed at $70 \mu \mathrm{m}$. The instrumental Gaussian-type full-width at half-maximum (FWHM) $\Delta \lambda_{\mathrm{I}}=$ $0.022 \mathrm{~nm}$ was measured to perform spectral line broadening of Balmer lines. The holographic diffraction gratingare: $1800 \mathrm{~mm}^{-1}$ blazed at $580 \mathrm{~nm}(450$ to $850 \mathrm{~nm})$ and $2400 \mathrm{~mm}^{-1}$ $(170$ to $500 \mathrm{~nm})$. The rotational and vibrational spectra of the molecules $\mathrm{N}_{2}$ and $\mathrm{OH}$ and the atomic spectral lines were visualized with computer software. Fig. 2 shows the optical magnification system used, consisting of two converging lenses. The image magnification was $A=f_{2} / f_{1}$, where $f_{2}$ is the focal distance of the projective lens. The corresponding spatial resolution was $R_{\ell}=L / A$, where $L$ is the entrance slit opening. To select a plasma volume for scanning, one should only move the projection lens in the $z$ direction (Fig. 2). A Princeton monochromator with focal length $f=0.5 \mathrm{~m}$, equipped with a set of holographic diffraction gratings and a CCD camera was used to obtain spectra in real time in the case of the determination of the electron excitation temperature.

\section{Results and Discussion}

The inset in Fig. 1a represents the photograph of air plasma jet. Fig. $1 \mathrm{~b}$ and $1 \mathrm{c}$ shows the Schlieren image of the plasma laminar outflow and a picture of the $\mathrm{N}_{2}$ microplasma jet system, respectively. As can be seen in Fig. 1b, the gas 
flow travels through the internal channels of the two electric spiral-type electrodes (diameter $D=2.5 \mathrm{~mm}$ ) forming a series of thin streams which begins to unite from the tip of the outer electrode, thus resulting in broaden and continuous laminar gas flow. The jet has a visible radial diameter of approximately $1.5 \mathrm{~mm}$ with afterglow surrounding the jet, as can be seen in Schlieren photography. Cylindrical shape plasma with high brightness is generated between the two electrodes (see Fig. 2c) and the intense gas flow drags this plasma to the external environment, forming a distended plasma plume. Once at the external environment, the mixture of the gas with the atmospheric air occurs, which significantly reduces the temperature of the plasma (afterglow). The jet elongates axially when the flow rate is increased, from 2 to $12 \mathrm{~L} / \mathrm{min}$, maintaining the laminar behavior. Electrical measurements were performed with a digital oscilloscope (Tektronix) with a high voltage and current probe $(1000 \mathrm{x})$. The gas temperature was measured by both a K-type thermocouple and optically. The emitted radiation by the microplasma was guided by optical fiber via entrance slit onto a Princeton monochromator (or onto the Jobin-Yvon monochromator)with focal length $f=0.5 \mathrm{~m}$, equipped with a set of holographic diffraction gratings and a CCD camera (see Fig.1a). Optical emission spectroscopy (OES) measurements were carried out in order to obtain mainly information about the excited species of the plasma $[6,7]$.
The voltage-current characteristic curves were found to be typical for ac glow discharges, showing voltage and current waveforms of the discharge, where the pre-breakdown phase of the input voltage of the power source has sine waveform $(f$ $=60 \mathrm{~Hz}$ ). When increasing the voltage one distortion of the voltage waveform and the discharge voltage is observed, composed of a number of pulses with amplitudes in the range $\left(0.1-4 \mathrm{kV}\right.$ sawtooth wave profile) for $V_{\mathrm{rms}}=1.2 \mathrm{kV}$ and $I_{\mathrm{m}}=$ $160 \mathrm{~mA}$ (for $\mathrm{N}_{2}$ gas flow rate of $8 \mathrm{~L} / \mathrm{min}$ ).

For individual mixtures between $\mathrm{O}_{2}, \mathrm{~N}_{2}$ and air with $1 \% \mathrm{Ar}$ and for pure $\mathrm{He}$ and Ar working gas, the intense lines of Ar I $4 p-4 s$ and $5 p-4 s$ transitions $(706.7,738.4,763.5,800.6$, 810.4, 416.4, 419.1, $420.1 \mathrm{~nm}$ ) and He emission spectrum $(447.2,501.6,587.6,776.8,706.5 \mathrm{~nm})$ have been observed. Boltzmann-plot method (BP) $[6,7]$ was performed with these lines to estimate the plasma electron excitation temperature $\left(T_{e x c}\right)$. The results are: for molecular gases with $1 \% \mathrm{Ar}, T_{\text {exc }}=0.64 \mathrm{eV}$, for pure $\mathrm{He}, T_{\text {exc }}=0.51 \mathrm{eV}$ and for $\mathrm{Ar}$, $T_{A r}=0.60 \mathrm{eV}$. The gas temperature $\left(T_{g}\right)$ appears to be an important factor when direct medical application is envisaged e.g. for treatment of different skin diseases like mycoses or other common fungal infection. As it has be seen later, temperature about $40^{\circ} \mathrm{C}$ of the plasma plume together with high electron oscillation energy and densities, turn this APMJ highly suitable for express treatment of these diseases.



Figure 3. Emission lines observed on optical spectra of $\mathrm{N}_{2}+1 \%$ Ar microplasma jet at a flow rate of $8 \mathrm{~L} / \mathrm{min}$ 
Further, the $\mathrm{OH}$ emission band at $306.4 \mathrm{~nm}$ was used to measure the radical rotational temperature $\left(T_{r o t}\right)$. Microplasma jet in near-partial local thermodynamic equilibrium (LTE) enables the application of BP in order to estimate the plasma parameters, such as the gas temperature estimated from emission bands of $\mathrm{OH}$ radical, deduced from the rotational spectrum of $\mathrm{OH}$ (first order, ultra-violet, $\mathrm{A}^{2} \Sigma^{+}$, $\left.v=0 \rightarrow X^{2} \Pi, v^{\prime}=0\right)[23]$. The populations of the excited state $\mathrm{OH}$ can be generated by direct dissociation of the electron excitation of water $\left(\mathrm{H}_{2} \mathrm{O}+\mathrm{e}-\rightarrow \mathrm{OH}(\mathrm{A})+\mathrm{H}+\mathrm{e}-\right)$ or by dissociative recombination of $\mathrm{H}_{2} \mathrm{O}^{+}\left(\mathrm{H}_{2} \mathrm{O}^{+}+\mathrm{e}-\rightarrow \mathrm{OH}(\mathrm{A})\right.$ $+\mathrm{H})$, where $\mathrm{H}_{2} \mathrm{O}^{+}$is formed by metastables and subsequent dissociative recombination. Measurements performed at the glow region (between electrodes - see Fig. 1c) for $8 \mathrm{~L} / \mathrm{min}$ results as: $T_{\text {air }}=110^{\circ} \mathrm{C}, T_{H e}=100^{\circ} \mathrm{C}, T_{\text {Nitrogen }}=120^{\circ} \mathrm{C}, T_{A r}=$ $120^{\circ} \mathrm{C}$ and $T_{\text {Oxigen }}=130^{\circ} \mathrm{C}$. Another estimates of the gas temperature were done at axial position $z=5 \mathrm{mmfrom}$ the tip of outer electrode using a thermocouple: $T_{\text {air }}=42^{\circ} \mathrm{C}, T_{\mathrm{He}}=$ $32^{\circ} \mathrm{C}, T_{\text {Nitrogen }}=40^{\circ} \mathrm{C}, T_{A r}=45^{\circ} \mathrm{C}$ and $T_{\text {Oxigen }}=48^{\circ} \mathrm{C}$. For axial position $z=10 \mathrm{~mm}$, the temperature of this high-pressure afterglow region approaches to the room temperature. One possible explanation is hidden in the higher gas velocity (very thin orifice) and the mixing of the working gas with the environmental cold air at those distances from the micro-nozzle (see Fig.1b).

The air APMJ produces ozone gas and atomic oxygen, nevertheless the working gas in use. In a future work, our aim will be to evaluate the production of $\mathrm{O}_{2} a^{1} \Delta g$ singlet oxygen (far infrared), a metastable state at $0.98 \mathrm{eV}$ above the ground state, easily produced with this device. The production of singlet oxygen has potential biological applications and it is very interesting for plasma-surface interactions with $\mathrm{OH}$ radical, like in the wettability modification of glass and polymers surface. Fig. 3 shows the emission lines from $\mathrm{N}_{2}+1 \% \mathrm{Ar}$ microplasma jet at a flow rate of $8 \mathrm{~L} / \mathrm{min}$. One can see Ar I $4 p-4 s$ and $5 p-4 s$ and Ar II $4 p-4 s$ and $4 p-3 d$ transitions originated from higher energy levels. The $\mathrm{OH}, \mathrm{NO}, \mathrm{NH}$ and $\mathrm{N}_{2}$ spectra commonly appear in open-air atmospheric pressure discharges due to impurities and air wrapping up the plasma volume. From 500 to $900 \mathrm{~nm}$ strong $\mathrm{N}$ and $\mathrm{O}$ atomic and molecular $\mathrm{N}_{2}$ lines appears. The analysis of the emission lines of these molecules and atoms allows estimation of the microplasma parameters, such as temperatures modes.

Using the continuity equation for incompressible mass flow $(\Psi)$ one can evaluate the laminar behavior of the jet observed even at high flow rate. The conservation of mass at the interelectrode gap can be written as $\Psi_{\text {in }}=\Psi_{\text {out }}$, or $(\rho v)_{\text {in }}=$ $(\rho v)_{\text {out }}$, where $\rho$ is the specific mass of the gas (air) and $v$ is the gas velocity, given as $v=\Phi / \pi R^{2} \rho$, where $\Phi$ is the flow rate defined as $\Phi=\Psi / \rho$ and $D=2 R=2.5 \mathrm{~mm}$ is the hole diameter. At room temperature of $20^{\circ} \mathrm{C}, T_{\text {in }}=20^{\circ} \mathrm{C}$ and $\rho_{\text {in }}=$ $1,205 \mathrm{Kg} / \mathrm{m}^{3}$ and $T_{\text {out }}=110^{\circ} \mathrm{C}$ (measured with spectroscopic apparatus at the center of the glow discharge - plasma bulk between the electrodes - see Fig. 1a) for air flow rate $\Phi=$ $8 \mathrm{~L} / \mathrm{min}$ and $\rho_{\text {out }}=0.921 \mathrm{Kg} / \mathrm{m}^{3}$. Therefore, the gas velocity is only $v_{\text {out }}=35.6 \mathrm{~m} / \mathrm{s}$. Mohamed et al. [12] studied microhollow cathode plasma jet with $D=200 \mu \mathrm{m}$ and the gas velocity was $316 \mathrm{~m} / \mathrm{s}(\Phi=0.14 \mathrm{~L} / \mathrm{min})$ for $T_{\text {out }}=1500 \mathrm{~K}$, leading to a turbulent flow transition and subsequent reduction of plasma axial length. Our microjet diameter is $D$ $=2500 \mu \mathrm{m}, 13$ times greater, reducing significantly the effect of turbulence and gas temperature. Calculating the Reynolds number $R e=2 \rho v R / \mu$, where $\mu$ is the gas viscosity $\left(\mu_{\text {out }}=\right.$ $22.23 \times 10^{-6} \mathrm{~Pa}$.s for $T_{\text {out }}=110^{\circ} \mathrm{C}$ ), one can obtain $R e=3687$. Considering air flow in a pipe, turbulent flow occurs when $R e^{>} 4000$. The laminar regime in our investigations was observed from 2 to $12 \mathrm{~L} / \mathrm{min}$ flow rate, approximately obeying the Reynolds number parameters for air flow [24].

The electron number density $\left(n_{e}\right)$ can be obtained from Balmer line broadening, $\mathrm{H}_{\beta}[6,7]$. Unfortunately, this line has low intensity for all gases, and indicates densities lower than $10^{14} \mathrm{~cm}^{-3}$. Thus, $n_{e}$ can be roughly estimated from $n_{e}=$ $J /\left(\varepsilon \mu_{e} e\right)$, where $J$ is the current density, $\varepsilon$ is the mean electric field and $\mu_{e}$ is the electron mobility. The latter is given by $\left(\mu_{e} P\right)_{1}=T_{\text {gas }}\left(\mu_{e} P\right)_{2} / T_{\mathrm{o}}$, where $\left(\mu_{e} P\right)_{1}=0.42 \times 10^{6} \mathrm{~cm}^{2}$ Torr $/$ Vs is related to room temperature $\left(T_{0}=293 \mathrm{~K}\right)$ for $\mathrm{N}_{2}$ flowing gas. According to the discharge parameters mentioned earlier, $\mu_{e}=0.08 \mathrm{~m}^{2} / \mathrm{Vs}$ at $T=383 \mathrm{~K}, \varepsilon=1.2 \times 10^{6} \mathrm{~V} / \mathrm{m}, J=$ $8.4 \times 10^{4} \mathrm{~A} / \mathrm{m}^{2}$ and finally, $n_{e} \sim 10^{13} \mathrm{~cm}^{-3}$. These results are analogous to the result obtained by Hong et al. [9] for ac APMJ operated at $20 \mathrm{kHz}$.

This APMJ was used for polyethylene (PE) surface modification and this application was investigated through Water Contact Angle (WCA) measurements using DI water droplet. This organic substrate is characterized by long linear molecules $\left(-\mathrm{H}_{2} \mathrm{C}-\mathrm{CH}_{2}-\right)$ and has crystallinity between 85 and 95\% depending also on the molecular weight and its distribution, in addition to the conditions of the crystallization kinetics. Polyethylene is a thermoplastic characterized with high hydrophobicity, presenting the WCA at about $105^{\circ}$. Plasma surface treatments can increase the wettability of the polymer surface, changing the morphology and surface properties.

The wide range of chemical species present in the plasma offers numerous possibilities for modifying the atmosphere that covers the surface of the material to be treated, thus altering the chemical and morphological nature of this surface. The aim of this work is to turn the PE wettable surface after exposed the substrate foil to the APMJ. The optimum distance between the treated surface and the APMJ exit nozzle was about $5 \mathrm{~mm}$. Therefore, the treatment was done at axial position $z=5 \mathrm{~mm}$ from the tip of outer electrode using a range of gases, where the gas temperature was: $T_{\text {air }}=42^{\circ} \mathrm{C}, T_{H e}=32^{\circ} \mathrm{C}, T_{\text {Nitrogen }}=40^{\circ} \mathrm{C}, T_{A r}=45^{\circ} \mathrm{C}$ and $T_{\text {Oxigen }}=48^{\circ} \mathrm{C}$. At this distance, the rate of density of active species enables the surface modification for a reasonable exposure time.

Table 1 show the results obtained from the treatment. The input power of the APMJ was $6.0 \mathrm{~W}$ and the flow rate $\Phi=$ $8 \mathrm{~L} / \mathrm{min}$, for $\mathrm{N}_{2}$, air, $\mathrm{O}_{2}, \mathrm{He}$ and Ar. In this table, $\theta_{\min }$ is related to the minimum WCA after the 4 min treatment. We 
observed the saturation of the surface modification for longer exposure times, above 3.5 - $4 \mathrm{~min}$ for these gases. This last time was the best for aiming the minimum degree of the WCA. As we observed before, the active species produced in the plasma by chemical reactions or by sputtering processes were swept to the surface of the polymer due to the gas flow, acting on the surface modification and increasing the wettability.

Table 1. Parameters used for the surface treatment

\begin{tabular}{|c|c|c|c|c|}
\hline gas & $\theta_{\min }(\mathrm{deg})$ & Time $(\mathrm{min})$ & $\mathrm{P}(\mathrm{W})$ & $\Phi(\mathrm{L} / \mathrm{min})$ \\
\hline $\mathrm{N}_{2}$ & 30 & 4 & 6.0 & 8.0 \\
\hline air & 45 & 4 & 6.0 & 8.0 \\
\hline $\mathrm{O}_{2}$ & 70 & 3.5 & 6.0 & 8.0 \\
\hline $\mathrm{He}$ & 35 & 4 & 6.0 & 8.0 \\
\hline $\mathrm{Ar}$ & 55 & 3.5 & 6.0 & 8.0 \\
\hline
\end{tabular}

\section{Conclusions}

The proposed ac APMJ device could produce stable long and cold microjets from various working atomic and molecular gases, as Ar, $\mathrm{He}, \mathrm{N}_{2}, \mathrm{O}_{2}$ and air. This APMJ was built as a pencil-type device, suitable for various applications and research due to its low gas temperature and low cost materials in use, such as a commercial neon-lamp transformer and air compressor. Boltzmann-plotmethod was performed to estimate the excitation temperature $\left(T_{e x c}\right)$. The results are: for molecular gases with $1 \% \mathrm{Ar}, T_{\text {exc }}=0.64 \mathrm{eV}$, for pure He, $T_{e x c}=0.51 \mathrm{eV}$ and for Ar, $T_{A r}=0.60 \mathrm{eV}$. Gas temperature measurements performed at the glow region for $8 \mathrm{~L} / \mathrm{min}$ results as: $T_{\text {air }}=110^{\circ} \mathrm{C}, T_{H e}=100^{\circ} \mathrm{C}, T_{\text {Nitrogen }}=120^{\circ} \mathrm{C}$, $T_{A r}=120^{\circ} \mathrm{C}$ and $T_{\text {Oxigen }}=130^{\circ} \mathrm{C}$. At axial position $z=5 \mathrm{~mm}$ from the tip of outer electrode using a thermocouple, $T_{g}$ is: $T_{\text {air }}=42^{\circ} \mathrm{C}, T_{H e}=32^{\circ} \mathrm{C}, T_{\text {Nitrogen }}=40^{\circ} \mathrm{C}, T_{A r}=45^{\circ} \mathrm{C}$ and $T_{\text {Oxigen }}=48^{\circ} \mathrm{C}$. For axial position $z=10 \mathrm{~mm}$, the $T_{g}$ for afterglow region approaches to the room temperature. The capacity of operation with molecular and atomic (noble) gases, including air, is important for various technological applications, but the novelty of this APMJ is the electrodes performance in spiral-type spring, allowing broadening of the plasma plume at the outer electrode with diameter of 2.5 mmand, consequently, a higher surface area treatment. The APMJ was used for polyethylene (PE) surface modification and this modification was investigated through Water Contact Angle (WCA - $\theta$ ) measurements. The treatment was done at axial position $z=5 \mathrm{~mm}$ from the tip of outer electrode using a range of gases, where the gas temperature was: $T_{\text {air }}=42^{\circ} \mathrm{C}, T_{H e}=32^{\circ} \mathrm{C}, T_{\text {Nitrogen }}=40^{\circ} \mathrm{C}, T_{A r}=45^{\circ} \mathrm{C}$ and $T_{\text {Oxigen }}=48^{\circ} \mathrm{C}$. At input power of about $6.0 \mathrm{~W}$ and flow rate $\Phi=8 \mathrm{~L} / \mathrm{min}$, for $\mathrm{N}_{2}$, air, $\mathrm{O}_{2}, \mathrm{He}$ and $\mathrm{Ar}, \theta_{\min }(\mathrm{deg})$ is related to the minimum WCA after the 4 min treatment: $\mathrm{N}_{2}, \theta_{\min }=30$; air, $\theta_{\min }=45 ; \mathrm{O}_{2}, \theta_{\min }=70 ; \mathrm{He}, \theta_{\min }=35 ; \mathrm{Ar}, \theta_{\min }=55$.

\section{ACKNOWLEDGMENTS}

The authors acknowledge the financial support of the programs CAPES, FAPESP and CNPq for the partial financial support under Grant No. FAPESP/12/13064-4, CNPq/MCTI/SECIS406035/2013-0, CNPq/310419/2012-3 DT and CAPES/88881.030340/2013-01 BJT.

\section{REFERENCES}

[1] R. Caetano, Y. D. Hoyer, I. M. Barbosa, K. G. Grigorov, and B. N. Sismanoglu, Int. J. Mod. Phys. B27, 1350089 (2013).

[2] Y. D. Hoyer, B. N. Sismanoglu, and K. G. Grigorov, The Eur.Phys. J. D66,1712012 (2012).

[3] B. N. Sismanoglu, K. G. Grigorov, R. A. Santos, R. Caetano, M. V. O. Rezende, Y. D. Hoyer, and V. W. Ribas, The Eur. Phys. J. D 60, 479 (2010).

[4] B. N. Sismanoglu, K. G. Grigorov, R. Caetano, M. V. O. Rezende, Y. D. Hoyer, The Eur. Phys. J. D60, 505 (2010).

[5] M.P. Gomes, B.N. Sismanoglu, and J. Amorim, Braz. J. Phys.39, 25 (2009).

[6] B.N. Sismanoglu, J. Amorim, J.A. Souza-Corrêa, C. Oliveira, M.P. Gomes, Spectroch. Acta Part B64, 1287 (2009).

[7] C. Oliveira, J. A. Souza Corrêa, M. P. Gomes, B. N. Sismanoglu, and J. Amorim, Appl. Phys. Lett.93, 041503 (2008).

[8] K. H. Becker, K. H. Schoenbach, and J. G. Eden, J. Phys. D: Appl. Phys.39, R55 (2006).

[9] Y. C. Hong, and H. S. Uhm, Appl. Phys. Lett.89, 221504 (2006).

[10] K. Kim, G. Kim, Y. C. Hong, and S. S. Yang, Microel. Eng.87, 1177 (2010).

[11] B. Gielniak, T. Fiedler, and J. A. C. Broekaert, Spectroch. Acta Part B66, 21 (2011).

[12] A. -A. H. Mohamed, J. F. Kolb, and K. H. Schoenbach, Eur. Phys. J. D.60, 517 (2010).

[13] L. Giuliani, d. Grondona, H. Kelly, and F. Minotti, J. Phys.: Conf. Series370, 012011 (2012).

[14] Y. Hong, S. Yoo, and B. Lee, J. of Electrost.69, 92 (2011).

[15] J. McKenna, J. Pate, S. Mitra, N. Soin,V. Svrcek, P. Maguire, and D. Mariotti, Eur. Phys. J. Appl. Phys. 56, 24020 (2011).

[16] José Gregório, Olivier Leroy, Philippe Leprince, Caroline Boisse-Laporte, and Luís L. Alves, IEEE Transactions On Plasma Science, 39, NO. 11, (2011).

[17] Wei Dong Zhu and Jose L Lopez, Plasma Sources Sci. Technol. 21034018 (10pp) (2012).

[18] Yongcheol Hong, Seungryul Yoo, Bongju Lee, Journal of Electrostatics 69,92-96 (2011). 
[19] J Benedikt, V Raballand, A Yanguas-Gil, K Focke and A von Keudell, Plasma Phys. Control. Fusion 49, B419-B427 (2007).

[20] A. A. H. Mohamed et al., Eur. Phys. J. D 60, 2 (2010).

[21] Y. C. Hong, H. S. Uhm, and W. Ju. Yi, App. Phys. Lett.93, 051504 (2008).
[22] J. W. Bradley, J. S. Oh, O. T. Olabanji, C. Hale, R. Mariani, and K. Kontig, IEEE Trans. on Plasma Sci.39, 2312 (2011).

[23] G. H. Dieke, and H. M. Crosswhite, J. Quant. Spectrosc. Radiat.Transfer.2, 97 (1962).

[24] Holman, J. P. Heat Transfer. (MCGrau-Hill, New York, 2002) p. 207. 